\title{
A panaceia dos anticoagulantes na infecção pela COVID-19
}

\author{
Anticoagulants as panacea in COVID-19 infection
}

\author{
Marcone Lima Sobreira', Marcos Arêas Marques ${ }^{2,3}$ (D) \\ Como citar: Sobreira ML, Marques MA. A panaceia dos anticoagulantes na infecção pela COVID-19. J Vasc Bras. \\ 2020;19:e20200063. https://doi.org/10.1590/1677-5449.200063
}

A associação entre infecções virais, como a do vírus da imunodeficiência humana (HIV), hepatite $\mathrm{C}$ e influenza, e o tromboembolismo venoso (TEV) já está bem estabelecida na literatura médica e já havia voltado a ser evidência na comunidade científica na epidemia de Chicungunha e Zika ocorrida em 2017 $7^{1,2}$. A atual pandemia mundial de COVID-19, iniciada em Wuhan (China), causada pela cepa SARS-CoV-2 do coronavírus já infectou cerca de 310.000 brasileiros, com mais de 20.000 mortes aproximadamente, segundo dados do Ministério da Saúde ${ }^{3}$.

Apesar de seu amplo espectro clínico, que varia desde a forma assintomática até uma síndrome respiratória aguda grave (SARS) ${ }^{4}$, tem chamado atenção dos angiologistas e dos cirurgiões vasculares os sintomas relacionados à inflamação do sistema vascular e à hipercoagulabilidade que levam a manifestações como vasculite de pequenos vasos e trombose micro e macrovascular de artérias e/ou veias. Outro dado que chamou atenção desde o início foi a relação entre a elevação do dímero-D (DD) e o mau prognóstico da doença ${ }^{5}$, demonstrando uma clara associação entre o agravamento do quadro inflamatório sistêmico e o estado pró-trombótico resultante ${ }^{6}$.

Com o aumento progressivo dos números de casos graves da COVID-19, houve uma constatação mundial da alta incidência de trombose venosa profunda e embolia pulmonar nesse perfil de pacientes, mesmo com a farmacoprofilaxia ou anticoagulação plena teoricamente adequada para pacientes clínicos internados ${ }^{7}$. Nesse contexto descrito anteriormente, é de se esperar que haja um aumento progressivo de publicações relacionando o TEV à infecção por COVID-19 na literatura médica, visando compartilhar o ainda pequeno conhecimento sobre essa nova infecção.

Entretanto, apesar da crescente rede de pesquisas que se criou em torno da COVID-19, nota-se que a maioria desses estudos tem evidência fraca, pois o que se tem até o momento são, de uma forma geral, diretrizes de sociedades de especialidades, opiniões de especialistas, estudos in vitro, relatos de casos e algumas séries de casos (com tamanho amostral reduzido). Além disso, junto a essa explosão de publicações, nos deparamos com diversas teorias e normatizações a respeito da profilaxia e tratamento do TEV, mensurações seriadas do DD e o uso de anticoagulantes nas mais variadas posologias nesses pacientes, sem evidências científicas adequadas, até pela falta de tempo hábil para produzi-las.

O que se pode elucubrar de fato, até o momento, é que a infecção pelo SARS-CoV-2 parece carregar potencial trombogênico aumentado, com repercussões em microcirculação pulmonar, podendo haver algum benefício, ainda a ser comprovado, de anticoagulação sistêmica ${ }^{8}$. É importante ressaltar que, em se tratando de anticoagulantes, é necessário sempre contrabalançar o binômio risco/benefício, pesando a sua potencial eficácia: prevenção de trombose em microcirculação pulmonar e, também, em território arteriolocapilar ${ }^{9}$ contra o risco de complicações, como o sangramento.

Alguns relatos de autores chineses sugerem a melhora clínica de pacientes infectados pelo SARS-CoV-2 com o uso parenteral de anticoagulação, notadamente a heparina de baixo peso molecular (HBPM); entretanto, vale a ressalva que a falta de critério na indicação de terapia anticoagulante, com consequente uso indiscriminado de anticoagulação, pode não trazer benefício aos pacientes ${ }^{10}$, sendo muito temerário estabelecer como protocolo de conduta de uma forma generalizada. O efeito benéfico da heparina nesses pacientes [HNF (heparina não fracionada) ou HBPM] parece ser multifacetado. Além dos conhecidos efeitos anticoagulante e anti-inflamatório, as heparinas parecem ter papel como protetor endotelial, por antagonizar 
as histonas que causam injuria endotelial e, portanto, microcirculatória, e um efeito antiviral por competir com o vírus pelo sítio de ligação da superfície celular ${ }^{11}$.

Temos que ter muito cuidado para não cair na panaceia do uso de anticoagulantes de forma desenfreada, na profilaxia e no tratamento da evidente hipercoagulabilidade e suas manifestações clínicas que ocorrem nesses pacientes, especialmente apoiado em dosagens seriadas do DD, sem nos basearmos em ensaios clínicos multicêntricos, randomizados, duplos-cegos e controlados que possam atestar com confiabilidade a evidência científica necessária ao balizamento de condutas frente à doença e, principalmente, frente ao doente. Na falta desses estudos, podemos e devemos nos apoiar nas diretrizes existentes para tratamento e profilaxia do TEV em pacientes clínicos, pois elas são embasadas e validadas.

Mais recentemente, um painel de especialistas publicou um documento em que se discute, também, a racionalização do uso de anticoagulantes em pacientes COVID-19 positivos. Os autores sugerem que o paciente internado deva ser categorizado quanto ao risco de TEV para, então, receber a melhor profilaxia para cada caso específico. Em relação à extensão da profilaxia (especialmente a química), para pacientes no pós-alta, ainda não há subsídios que suportem a prescrição sistemática; sugere-se que os pacientes também sejam categorizados na alta quanto ao risco trombótico e hemorrágico, sendo, dessa forma, direcionados à melhor terapêutica, devendo ser todos orientados a se manter ativos enquanto confinados em ambiente doméstico. No que concerne à utilização de doses intermediárias ou terapêuticas de heparina para esses pacientes, ainda há controvérsia e polêmica: a maioria considera utilizar dose profilática, enquanto uma minoria acha razoável a utilização de dose plena ou intermediária para esse nicho de pacientes ${ }^{12}$.

O conhecimento a respeito da resposta dessa doença a qualquer tipo de tratamento sugerido está extremamente volúvel com renovação de conceitos diuturnamente, sendo necessários muito critério e parcimônia na tomada de conduta, procurando sempre ter em mente base científica palpável e sólida para não acarretar danos ao paciente.

\section{REFERÊNCIAS}

1. Marques MA, Adami de Sá FP, Lupi O, Brasil P, von Ristow A. Deep venous thrombosis and chikungunya virus. J Vasc Bras. 2017;16(1):60-2. http://dx.doi.org/10.1590/1677-5449.009616. PMid:29930626.

2. Ramacciotti E, Agati LB, Aguiar VCR, et al. Zika and chikungunya virus and risk for venous thromboembolism. Clin Appl Thromb Hemost. 2019;25:1-5. http://dx.doi.org/10.1177/1076029618821184. PMid:30808213.
3. Brasil. Ministério da Saúde. Coronavírus: Brasil registra 49.492 casos e 3.313 mortes. Brasília: Ministério da Saúde; 2020. [citado 2020 maio 20]. https://www.saude.gov.br/noticias/agencia-saude/46771coronavirus-brasil-registra-49-492-casos-e-3-313-mortes

4. Huang C, Wang Y, Li X, et al. Clinical features of patients infected with 2019 novel coronavirus in Wuhan, China. Lancet. 2020;395(10223):497-506. http://dx.doi.org/10.1016/S01406736(20)30183-5. PMid:31986264.

5. Han $\mathrm{H}$, Yang L, Liu R, et al. Prominent changes in blood coagulation of patients with SARS-CoV-2 infection. 2020. Clin Chem Lab Med. 2020. 2020. Epub ahead of print. http://dx.doi.org/10.1515/cclm2020-0188. PMid:32172226.

6. Klok FA, Kruip MJHA, van der Meer NJM, et al. Incidence of thrombotic complications in critically ill ICU patients with COVID-19. Thromb Research. 2020;191:145-7. https://doi.org/10.1016/j. thromres.2020.04.013.

7. Llitjos JF, Leclerc $M$, Chochois $C$, et al. High incidence of venous thromboembolic events in anticoagulated severe COVID-19 patients. J Thromb Haemost. 2020;1-4. http://dx.doi.org/10.1111/ jth.14869. PMid:32320517.

8. Negri EM, Piloto BM, Morinaga LK, et al. Heparin therapy improving hypoxia in COVID-19 patients - a case series. medRxiv - The Preprint Server for Health Sciences. 2020. Epub ahead of print. https://doi.org/10.1101/2020.04.15.20067017.

9. Gauna MEG, Bernava JL. Recomendaciones diagnósticas y terapéuticas ante la Respuesta Inmune Trombótica Asociada a COVID-19 (RITAC). Argentina: Bonamí Estudio Creativo; 2020. [citado 2020 abr 26]. https://fundacionio.com/wp-content/ uploads/2020/04/Si\%CC\%81ndrome-RITAC.pdf.pdf.pdf.pdf.pdf. pdf.pdf

10. Tang N, Bai H, Chen X, et al. Anticoagulant treatment is associated with decreased mortality in severe coronavirus disease 2019 patients with coagulopathy. J Throm Haemost. 2020(18)5:1094-99. http:// dx.doi.org/10.1111/jth.14817.

11. Thachil J. The versatile heparin in COVID-19. J Thromb Haemost. 2020;18(5):1020-2. http://dx.doi.org/10.1111/jth.14821. PMid:32239799.

12. Bikdeli B, Madhavan MV, Jimenez D, et al. COVID-19 and thrombotic or thromboembolic disease: implications for prevention, antithrombotic therapy, and follow-up. J Am Coll Cardiol. 2020. Epub ahead of print. http://dx.doi.org/10.1016/j.jacc.2020.04.031.

Correspondência Marcos Arêas Marques Rua Assunção, 217/704 - Botafogo CEP 22251-030 - Rio de Janeiro (RJ), Brasil

Tel.: (21) 99859-0160

E-mail:mareasmarques@gmail.com

Informaç̧ões sobre os autores MLS - Professor Adjunto Livre-Docente, Divisão de Cirurgia Vascular e Endovascular, Faculdade de Medicina de Botucatu, Universidade Estadual Paulista (UNESP). MAM - Médico angiologista, Unidade Docente Assistencial de Angiologia, Hospital Universitário Pedro Ernesto, Universidade do Estado do Rio de Janeiro (UERJ); Médico angiologista, Serviço de Cirurgia Vascular, Hospital Universitário Gaffrée e Guinle, Universidade Federal do Estado do Rio de Janeiro (UFRJ). 